\title{
Unusual presentation of an obstetrical urethrovaginal fistula secondary to improper catheter placement
}

\author{
Anne P. Cameron, MD; Humphrey 0. Atiemo, MD
}

\begin{abstract}
Vesicovaginal and urethrovaginal fistulas related to obstetrical causes are exceptionally rare in the developed world. We report a case of 23-year-old woman with a urethrovaginal fistula, which developed after a cesarean delivery because of an inappropriately placed urethral catheter. Diagnostic evaluation and surgical approach are discussed.
\end{abstract}

Can Urol Assoc J 2009;3(4):E21-E22

\section{Introduction}

A 23-year-old woman (gravida 3 para 4) presented to the urology clinic with severe stress and urge incontinence that had been present since her second child was born. After her first pregnancy with an uncomplicated cesarean delivery the patient reported normal continence postpartum. Before her second delivery, again via elective cesarean delivery, she had a $16 \mathrm{~F}$ catheter placed per urethra after epidural anesthesia. The infant had a compound presentation with the right arm along the side of the head. It was also noted during the surgery that the bladder was distended, which made access to the uterus difficult. Postoperatively, the patient was noted to have no urine draining out of the catheter, so a vaginal examination was performed. A significant urethravaginal fistula was noted with the catheter balloon seen inflated in the location of the midurethra. A urologist was consulted who primarily repaired the fistula by placement of figure-of-8 suture ligature. After 1 month of catheter drainage, a subsequent cystoscopy showed resolution of the injury.

Soon after, however, the patient developed increasing stress and urge incontinence, but did not seek medical treatment since she was pregnant again. During catheter placement before her third cesarean delivery she was found to have a recurrence of her urethrovaginal fistula. Vaginal examination revealed the catheter and its balloon to be within the vagina, having exited via the urethrovaginal fistula.
The patient presented to our care in the postpartum period for management of her urethrovaginal fistula and incontinence. Her severe incontinence that had been present since her second delivery required heavy diapers and she recounted rarely voiding because of her amount of incontinence. On physical examination the urethral meatus was difficult to locate and appeared obliterated, preventing insertion of a catheter. A midurethral fistula was seen and was able to admit a $16 \mathrm{~F}$ catheter that passed into the bladder. The vaginal epithelium was otherwise healthy.

A clinical decision to perform a transvaginal closure of this fistula with the use of an autologous fascial sling was discussed with the patient, who agreed with the treatment plan. Under general anesthesia a more detailed examination and cystoscopy of the distal urethra demonstrated patency and viability of the distal urethra allowing maintenance of the urethral integrity. An inverted u-shaped incision was made in the anterior vaginal wall at the proximal edge of the fistula. The fistula was then circumscribed, with care taken not to enlarge it (Fig. 1). After a conservative urethrolysis the fistula was closed vertically over an $18 \mathrm{~F}$ catheter using interrupted absorbable sutures. A preserved layer pubocervical fascia that was created during the dissection was used as a second layer to cover the urethral closure.

A pubovaginal sling was then performed in the manner described by Chaikin and colleagues. ${ }^{1}$ This autologous fascial sling provided an anti-incontinence procedure as well as an additional layer for the fistula closure. No Martius flap was needed secondary to the 3-layer closure that was achieved with preservation of the pubocervical fascia. Finally the inverted u-shaped vaginal incision was closed, providing no overlapping suture lines and 4 layers of closure of the fistula. The patient was discharged home 1 day after surgery with a urethral catheter in place. Three weeks later a voiding cystourethrogram demonstrated no fistula recurrence with complete emptying of the bladder, so her catheter was removed. At 3-month follow-up, the patient was continent, and had not had recurrence of her fistula or incontinence. 


\section{Discussion}

In the developed world, vesicovaginal and urethrovaginal fistulas following delivery are very rare. It is a very different story, however, in developing countries where obstetrically related

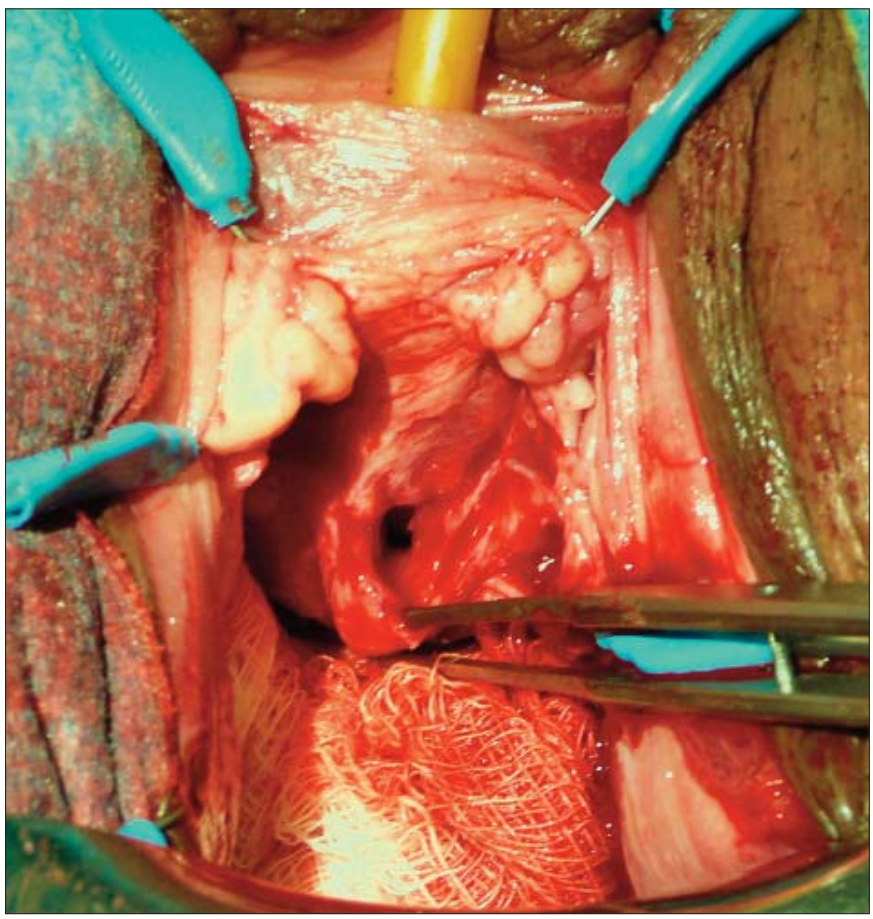

Fig. 1. Fistula in the midurethra. Inverted u-shaped vaginal flap has been dissected.

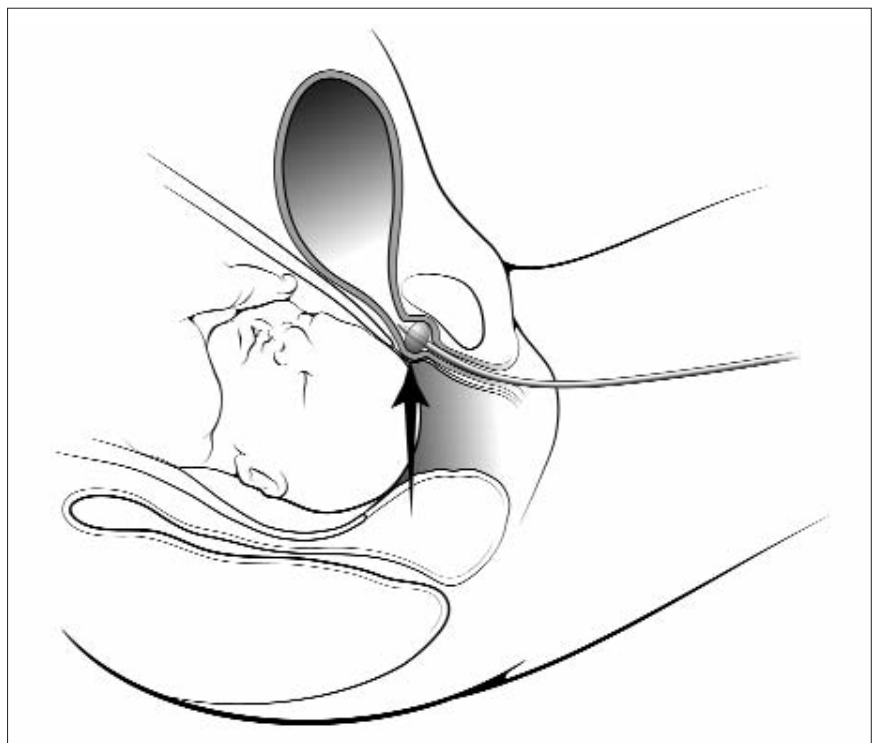

Fig. 2. Inflated urethral catheter balloon in the urethra (arrow) led to ischemia and rupture of the urethra creating a urethrovaginal fistula. fistulas are still endemic because of lack of obstetrical care. There are recent large-series reports on fistulas from Nigeria, where $96.5 \%-97.9 \% \%^{2,3}$ of these fistulas are a result of prolonged obstructed labour. This is unfortunately a disease of young women of poor socioeconomic status, who often waited several days before hospital presentation. ${ }^{3}$ In contrast, out of 17 obstetrically related fistulas occurring in the United Kingdom from 1970 to 1988, none were from obstructed labour and these only comprised $10 \%$ of all vesicovaginal fistulas during that time period in Newcastle upon Tyne. ${ }^{3}$ In a US series, ${ }^{4} 91 \%$ of vesicovaginal fistulas occurred after hysterectomy, $4 \%$ after radiotherapy and the remainder from trauma, foreign bodies, other vaginal surgeries and obstetrical causes.

In this case report, the improper placement of a urinary catheter unnoticed because of epidural anesthesia for a cesarean delivery, combined with pressure from the fetal head and arm seem to have been the inciting event. Fistulas from labour typically occur during the second stage when the bladder is displaced superiorly and the fetal head applies pressure on the anterior vaginal wall, with compression of the urethral bladder base and urethra against the pubic symphysis. ${ }^{3}$ A dilated catheter balloon within the midurethra had the same effects on the urethra, leading to ischemia and pressure necrosis with the development of a urethrovaginal fistula (Fig. 2). Catheter drainage during cesarean delivery is essential to provide decompression of the bladder and avoidance of bladder injury. Care should be taken to always obtain urinary drainage after catheter placement before inflation of the catheter balloon. Though this is a very rare mechanism for obstetrical fistula development, it reiterates the importance of catheter placement technique and the subsequent consequences of improper technique.

From the Department of Urology, University of Michigan, Ann Arbor, Mich.

This article has been peer reviewed.

Competing interests: None declared.

\section{References}

1. Chaikin DC, Rosenthal J, Blaivas JG. Pubovaginal fascial sling for all types of stress urinary incontinence: long term analysis. J Urol 1998;160:1312-6.

2. Wall LL, Karshima JA, Kirschner C, et al. The obstetric vesicovaginal fistula: characteristics of 899 patients from Jos, Nigeria. Am J Obstet Gynecol 2004;190:1011-9.

3. Lawson J. Tropical obstetrics and gynaecology. 3. Vesico-vaginal fistula - a tropical disease. Trans R Soc Trop Med Hyg 1989;83:454-6.

4. Eilber KS, Kavaler E, Rodriguez LV, et al. Ten-year experience with transvaginal vesicovaginal fistula repair using tissue interposition. J Urol 2003;169:1033-6.

Correspondence: Dr. Anne Cameron, 3875 Taubman Center, 1500 E. Medical Center Dr., Ann Arbor Ml 48109; annepell@med.umich.edu 